\title{
SIMULAÇÃo DE CENÁRIOS NA PRÓ-REITORIA DE GESTÃo DE PESSOAS DE UMA INSTITUIÇÃO DE EDUCAÇÃO SUPERIOR PÚBLICA DO OESTE DO PARANÁ
}

\section{RESUMO}

Num ambiente de frequentes mudanças, as organizações são constantemente influenciadas pelo ambiente em que atuam. Para as Instituições de Educação Superior a regra é a mesma, portanto, torna-se imprescindível a adoção de estratégias eficazes para o seu sucesso. Este relato técnico tem como objetivo a simulação de cenários na Pró-Reitoria de Gestão de Pessoas de uma Instituição de Educação Superior Pública localizada na região oeste do Paraná. Para isso, aplicou-se o modelo Rojo de Simulação de Cenários (ROJO, 2005) nesta pró-reitoria, uma vez que a prática de simulação de cenários não fazia parte de seu planejamento estratégico. Como contribuição, esta intervenção proporcionou a formulação de estratégias para três cenários projetados: um pessimista, um intermediário e um otimista. Ao final, elaborou-se um plano de ação contendo metas alinhadas às estratégias a fim de minimizar ou aproveitar as contingências futuras.

Palavras-chave: Estratégia; Cenários; Instituição de Educação Superior.

\section{SIMULATION OF SCENARIOS IN THE PRO-REITORIA OF MANAGEMENT OF PEOPLE OF AN INSTITUTION OF HIGHER PUBLIC EDUCATION OF THE WEST OF PARANÁ, BRAZIL}

\begin{abstract}
In an environment of frequent changes, organizations are constantly influenced by the environment in which they operate. For higher education institutions the rule is the same, therefore, becomes essential to the adoption of effective strategies for your success. This technical report aims to the simulation of scenarios on the Office of personnel management of a Public higher education institution located in the Western region of Paraná. For this, the Rojo model of simulation scenarios (ROJO, 2005) on this pró-reitoria, since the practice of simulation scenarios was not part of your strategic planning. As a contribution, this intervention resulted in the formulation of strategies for three scenarios designed: a pessimist, an intermediary and an optimist. In the end, drew up a plan of action containing goals aligned with strategies to minimize or take advantage of future contingencies.
\end{abstract}

Keywords: Strategy; Scenarios; Institution of Higher Education. 
Simulação de Cenários na Pró-Reitoria de Gestão de Pessoas de uma Instituição de Educação Superior Pública do Oeste do Paraná

\section{SIMULACIÓN DE ESCENARIOS EN EL PRO-REITORIO DE GESTIÓN DE PUEBLES DE UNA INSTITUCIÓN DE EDUCACIÓN PÚBLICA SUPERIOR DEL OESTE DE PARANÁ, BRASIL}

\section{RESUMEN}

En un entorno de cambios frecuentes, las organizaciones están constantemente influenciadas por el entorno en el que operan. Para las instituciones de educación superior, la regla es la misma, por lo tanto, se convierte en esencial para la adopción de estrategias eficaces para su éxito. Este informe técnico tiene como objetivo la simulación de escenarios en la Oficina de Gestión de Personal de una Institución Pública de Educación Superior ubicada en la región occidental de Paraná. Para ello, el modelo Rojo de escenarios de simulación (ROJO, 2005) sobre esta pró-reitoria, ya que la práctica de escenarios de simulación no formaba parte de su planificación estratégica. Como aporte, esta intervención resultó en la formulación de estrategias para tres escenarios diseñados: un pesimista, un intermediario y un optimista. Al final, elaboró un plan de acción que contenía metas alineadas con estrategias para minimizar o aprovechar las contingencias futuras.

Palabras clave: Estrategia; Escenarios; Institución de educación superior.

\footnotetext{
1 Mestrando do Programa de Pós-Graduação em Administração da Universidade Estadual do Oeste do Paraná UNIOESTE. Brasil. E-mail: rafaelnojima@ hotmail.com

${ }^{2}$ Especialização em Gestão Empresarial pela Universidade Federal do Rio Grande do Sul - UFRGS. Brasil. E-mail: carlosjacoby@gmail.com

${ }^{3}$ Doutor em Engenharia de Produção pela Universidade Federal de Santa Catarina - UFSC. Professor da Universidade Estadual do Oeste do Paraná - UNIOESTE. Brasil. E-mail: rojo_1970@ hotmail.com
} 


\section{INTRODUÇÃ̃O}

Num ambiente de frequentes mudanças em que as organizações desempenham suas atividades torna-se imprescindível a adoção de estratégias eficazes para o seu sucesso. A organização é constantemente influenciada pelo mercado, desta forma, a formulação da estratégia competitiva de uma organização é essencial relacioná-la ao ambiente em que está inserida (Porter, 1986).

Partindo-se do pressuposto que para as instituições de educação superior a regra seja a mesma, suas estratégias devem estar pautadas nas características do mercado e, no caso de instituições públicas, principalmente nas políticas de governo. Estas instituições possuem papel social e profissional importante perante aos alunos e a sociedade externa. Para a prestação de um serviço de qualidade precisam de estratégias efetivas para o enfrentamento de possíveis contingências do mercado.

Para Hoss et al. (2012) a simulação de cenários além de permitir uma melhor compreensão do ambiente, capacita a organização em como agir nas mais diferentes circunstâncias, esta ação corporativa envolve as experiências vividas por ela, a capacidade dos servidores e as expectativas que se tem do futuro. Estudos como o de Brandalise et al. (2012) e Hoss et al. (2012) citam a importância da simulação de cenários para as possíveis contingências ambientais. $\mathrm{O}$ pensar de modo prospectivo faz parte do raciocínio estratégico e é imprescindível ao administrador (Brandalise et al., 2012).

Diante do exposto, este relato possui a seguinte problemática: quais os possíveis cenários para uma instituição pública de educação superior tendo em vista a situação econômica do país? Desta forma, realizou-se a simulação de cenários estratégicos para Pró-Reitoria de Gestão de pessoas de uma Instituição de Educação Superior da região oeste do Paraná com base no modelo desenvolvido por Rojo (2005), com a intenção de compor seu planejamento estratégico. A simulação de cenários se apresenta como uma ferramenta que busca minimizar os possíveis eventos negativos futuros e auxiliar a organização nas tomadas de decisões estratégicas (Rojo, 2005). Evita-se assim que possíveis mudanças no ambiente possam afetar drasticamente as atividades da instituição futuramente.

O presente relato técnico está divido em seis seções: na primeira delas esta introdução; na segunda seção apresenta-se o referencial teórico quanto à estratégia organizacional, planejamento estratégico, cenários e o modelo de simulação de cenários; na terceira seção o método utilizado no relato; na quarta, descreve-se a situação problema; na quinta, apresentam-se os resultados obtidos e análises; e na última seção são tecidas as considerações finais.

\section{REFERENCIAL TEÓRICO}

\section{Estratégia}

No intuito de minimizar efeitos negativos as organizações estão sendo obrigadas a se estruturarem estrategicamente para alcançar a satisfação de seus clientes e consequentemente os desempenhos esperados. Mintzberg, Lampel, Quinn e Ghoshal (2006) afirmam que "uma estratégia bem formulada ajuda a organizar e alocar os recursos de uma organização em uma postura baseada em suas competências e deficiências internas relativas, mudanças antecipadas no ambiente e movimentos contingentes por parte dos oponentes inteligentes." (p. 29).

A percepção dos gestores quanto às mudanças ambientais pode fazer com que organizações concorrentes e inseridas num mesmo setor apresentem índices de desempenho diferentes, é a partir desta percepção de ambientes que as organizações podem traçar suas estratégias e se posicionarem adequadamente no mercado (Sokoloski, 2007). As principais preocupações dos administradores são com as incertezas e as mudanças ambientais que podem gerar ameaças ou oportunidades às organizações, estas mudanças acontecem em alta velocidade que o tempo de reação dos administradores não está mais sendo capaz de minimizar seus impactos (Ansoff \& McDonnell, 1993). Ao discorrer sobre as forças competitivas de uma indústria, Porter (1986) menciona o governo como um fator a ser considerado, pois dependendo das políticas adotadas, pode exercer o papel de comprador ou de fornecedor, influenciando diretamente nas análises estratégicas da organização. Portanto se faz necessária a consideração destes fatores no planejamento estratégico de uma instituição.

\section{Planejamento estratégico}

Para Hoss et al. (2012) "o planejamento estratégico permite vislumbrar uma organização sob vários ângulos, definindo seus rumos por meio de um direcionamento que possa ser monitorado nas suas ações concretas" (p.180). O planejamento estratégico pode ser definido como ações administrativas pautadas nos objetivos da organização e que visam o seu futuro, tornando mais rápida e eficaz a tomada de decisão (Oliveira, 1999).

Certo e Peter (1993) ao tratarem da administração estratégica destacam que os ambientes organizacionais estão em constantes modificações e que as organizações devem acompanhá-las para que suas metas sejam alcançadas. Uma das formas de prever estas contingências é fazendo o uso de cenários estratégicos como parte do planejamento nas organizações. Brandalise et al. (2012) apontam que 
prospectar cenários em ambientes como estes torna complexa a visão de futuro, por isso a simulação de cenários se apresenta como ferramenta gerencial diante das incertezas.

\section{Cenários}

Rojo (2005) explica que cenários são possibilidades simuladas do futuro, uma ferramenta cognitiva que busca descrever como determinada situação poderá se transformar, tendo como ponto de partida os eventos do momento presente. Estas informações simuladas minimizarão os possíveis riscos futuros por subsidiar o planejamento estratégico da organização.

Gonçalves, Torres, Rodrigues e Zygielszyper (2011) afirmam que “[...] mudanças nas variáveis macroeconômicas costumam ter grande potencial de interferência sobre o desempenho das organizações." (p.82). Ghemawat (2000) menciona que os administradores precisam ir além do potencial lucrativo de um mercado, eles devem se preocupar com mudanças importantes no cenário de negócios e se adaptar a elas. Na visão de Gonçalves et al. (2011) “[...] a atividade de planejamento com cenários se relaciona com a busca de uma visão de futuro [...] em um ambiente crescentemente dinâmico" (p. 19).

Assim, a construção de cenários significa a projeção de prováveis situações futuras que possibilitarão a criação de planos de ação e estratégicos para a instituição, onde as estratégias da organização são criadas a partir da análise de cenários (Tachizawa \& Rezende, 2002; HOSS et al., 2012). Desse modo, a simulação de cenários contribui com os objetivos organizacionais.

\section{Modelo Rojo de simulação de cenários}

O modelo utilizado é composto por cinco níveis conforme ilustrado na Figura 1 abaixo e que serão descritas logo adiante.

Figura 1 - Estrutura básica do modelo Rojo

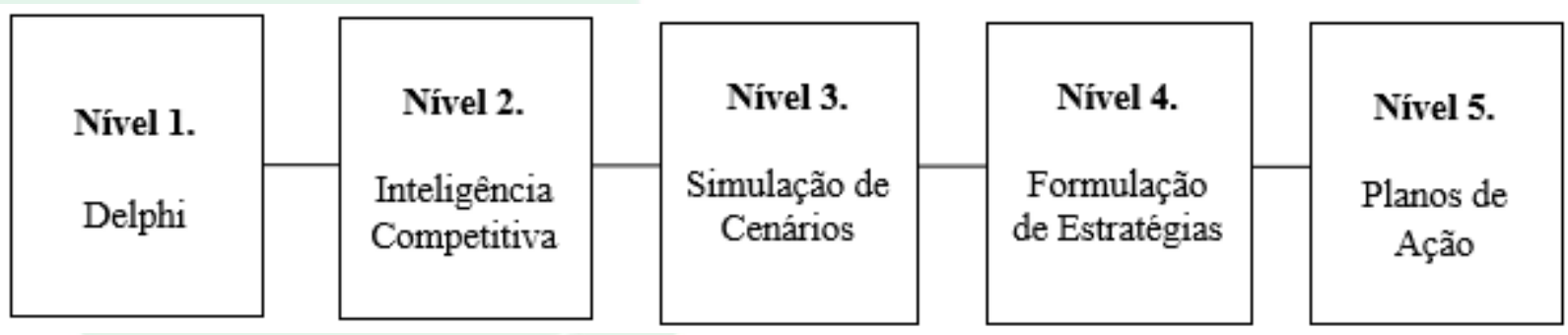

Fonte: Rojo (2005)

O primeiro nível trata-se da aplicação do método Delphi junto a diretores, gerentes, profissionais da instituição denominados especialistas por possuírem conhecimentos que possibilitarão a identificação de variáveis críticas relevantes à simulação de cenários. Rojo (2005) explica que o objetivo do método é auxiliar na capacidade de acertos das pesquisas por meio de experts profundamente envolvidos com a temática a ser estudada.

O segundo nível do modelo, denominada de inteligência competitiva aborda o uso de ferramentas administrativas vinculadas às informações coletadas na Delphi para análises estratégicas. Rojo (2005) afirma que não existe um número definido de ferramentas a serem utilizadas e que ainda é possível trocas destas em função da estratégia.

Após a aplicação das ferramentas o próximo passo é a simulação dos cenários. Rojo (2005, p. 129) explica que "cada cenário corresponde a uma antecipação de possíveis alterações contextuais". Gonçalves et al. (2011) corroboram ao indicar que o objetivo principal da formulação de futuros possíveis é a rápida tomada de decisão em situações novas ou adversas.

No quarto nível do modelo as estratégias são formuladas com base nos cenários elaborados anteriormente. Rojo (2005) destaca que um dos fatores a serem observados é a convergência com objetivos e metas para que cheguem aos resultados esperados. $\mathrm{O}$ autor ainda afirma que cada cenário possui um problema que requer uma estratégia de solução.

Por fim, o nível cinco transforma as estratégias em planos de ação com metas definidas e possíveis de serem executas, convergentes aos objetivos da organização e que servirão de base caso os cenários se concretizem (ROJO, 2005).

\section{MÉTODO}

\section{Método da produção técnica}

O estudo foi realizado entre os meses de agosto e setembro de 2015 e utilizou uma abordagem 
qualitativa caracterizada como pesquisa-ação tendo em vista a participação efetiva dos pesquisadores. Para Godoy (1995) a pesquisa qualitativa valoriza o contato direto do pesquisador com o ambiente e a situação estudada. Thiollent (2011) afirma que a pesquisa-ação não se trata de simples levantamento de dados, ela é encarada como uma estratégia de pesquisa social por meio da interação entre pesquisadores e participantes.

Para o desenvolvimento das atividades na instituição de educação superior - IES, utilizou-se da participação direta dos pesquisadores com os especialistas da pró-reitoria de gestão de pessoas PROGEPE, e principalmente com o pró-reitor, cargo máximo desta unidade. Um dos pesquisadores é servidor da instituição e trabalha na pró-reitoria de gestão de pessoas, o que facilitou os estudos por já possuir certo conhecimento da unidade estudada e por ter acesso aos especialistas. Visando uma maior quantidade e qualidade dos dados coletados sobre o ambiente das IES, em certa etapa dos estudos, especialistas de outra instituição de educação superior foram consultados tendo em vista a semelhança das características das instituições.

Diante disso, a intervenção realizada se enquadra como consultoria tendo em vista que todo o resultado alcançado ficou a cargo da unidade utilizar ou não como parte integrante de seu planejamento estratégico. Para o desenvolvimento das atividades do relato técnico foram utilizadas pesquisas documentais, aplicação de questionários para a identificação das variáveis críticas dos cenários e entrevistas não estruturadas entre o pró-reitor e os pesquisadores. Estas técnicas possibilitaram a triangulação das informações coletadas dando assim maior confiabilidade nos resultados do trabalho. A utilização de várias práticas interpretativas possibilita várias formas diferentes de visualizar o ambiente, portanto para melhor compreender o fenômeno existe um compromisso no emprego de mais de uma prática no estudo (Denzin \& Lincoln, 2006).

\section{Situação-problema}

A pró-reitoria de gestão de pessoas, objeto de estudo deste relato, faz parte de uma instituição de educação superior que possui natureza jurídica de autarquia e é mantida pela União. Sua operação foi iniciada no ano de 2010 e desde lá as atividades o quadro de servidores tem aumentado, atingindo 845 (oitocentos e quarenta e cinco) servidores atualmente, entre técnicos administrativos e professores. Ela ainda conta com aproximadamente 2.500 (dois mil e quinhentos) discentes divididos entre os 36 cursos ofertados.
Anualmente todas as pró-reitorias da instituição elaboram seu planejamento estratégico para o ano subsequente e a gestão administrativa da instituição se dá pela articulação entre estas unidades e a reitoria. $\mathrm{Na}$ PROGEPE não foi identificada a prática de simulação de cenários como parte integrante de seu planejamento estratégico, portanto, com o objetivo de complementar seu planejamento estratégico, este estudo visa simular possíveis cenários para a pró-reitoria.

No início do ano de 2015, as instituições de educação superior federais tiveram seus orçamentos reduzidos em $30 \%$ devido ao atraso da aprovação da Lei Orçamentária Anual - LOA de 2015 (Brasil, 2015), o que acarretou diversas consequências para as instituições de ensino. Devido ao fato já ocorrido, utilizado como exemplo, a aplicação do modelo de simulação de cenários de Rojo se apresenta como complementação às estratégias adotadas por estas instituições, na tentativa de minimizar os efeitos negativos destes acontecimentos.

\section{RESULTADOS}

\section{Nível 1: Delphi}

No nível 1 do modelo utilizado é aplicada a técnica de coleta de dados Delphi, divida em três rodadas. Para a seleção dos participantes da primeira rodada foram considerados os gestores que desempenham atividades e possuem experiência na área de gestão de pessoas em instituições de educação superior, configurados como especialistas a partir de então. Os questionários foram entregues via correio eletrônico aos especialistas de duas IES do oeste do Paraná para a identificação das variáveis críticas que darão origem aos cenários.

A distribuição foi da seguinte forma: na instituição da pró-reitoria estudada foram quatro questionários para os respectivos gestores do Departamento de Administração de Pessoal, Departamento de Desenvolvimento Profissional e Pessoal, Departamento de Promoção e Vigilância à Saúde e um para o Pró-Reitor de Gestão de Pessoas. Na outra instituição de educação superior foi entregue apenas um questionário, entretanto, foi preenchido em conjunto por especialistas da instituição.

Destaca-se que as duas instituições questionadas possuem estruturas organizacionais similares e são orientadas pelas mesmas legislações e/ou semelhantes, então, considerou-se convergente a visão de cenários dos especialistas das instituições.

A Figura 2 demonstra as variáveis críticas identificadas na aplicação da primeira rodada da Delphi com os especialistas. 
Simulação de Cenários na Pró-Reitoria de Gestão de Pessoas de uma Instituição de Educação Superior Pública do Oeste do Paraná

Figura 2 - Primeira rodada Delphi

\begin{tabular}{|c|}
\hline Variáveis Críticas \\
\hline Orçamento \\
\hline Infraestrutura \\
\hline Política Interna da IES \\
\hline Cenário Político Externo \\
\hline Quadro de Servidores da IES \\
\hline Planejamento \\
\hline Comunicação Interna \\
\hline Plano de Carreira dos Servidores \\
\hline Rotatividade dos Servidores \\
\hline Tecnologia e Sistemas de Informação \\
\hline Capacitação e Qualificação do Servidor \\
\hline Estrutura Organizacional \\
\hline Legislação \\
\hline Clima Organizacional \\
\hline Proatividade dos Servidores \\
\hline Função Política e Social das IES \\
\hline Competição \\
\hline Expansão e Reestruturação das IES \\
\hline Perfil do Servidor Ingressante \\
\hline
\end{tabular}

Fonte: elaborado pelos autores (2016)

Na segunda rodada da Delphi foram enviados novos questionários aos especialistas solicitando que os mesmos avaliassem e indicassem dentre todas as variáveis críticas levantadas às cinco mais importantes para simulação de cenários na opinião deles.
A seleção das cinco variáveis críticas foi feita por meio de uma escala, sendo o peso 5 para o mais importante, 4 para importante, 3 para média importância, 2 para pouco importante e 1 para menos importante (ROJO, 2005). O resultado é apresentado na Figura $3 \log$ abaixo. 
Simulação de Cenários na Pró-Reitoria de Gestão de Pessoas de uma Instituição de Educação Superior Pública do Oeste do Paraná

Figura 3 - Segunda rodada Delphi

\begin{tabular}{|c|c|c|c|c|c|c|}
\hline \multirow{2}{*}{ Variáveis Críticas } & \multicolumn{5}{|c|}{ Respostas da Segunda Rodada } \\
\hline & A & B & C & D & E & Peso Total \\
\hline Orçamento & 3 & 4 & & 4 & & 11 \\
\hline Infraestrutura & 2 & & & & & 2 \\
\hline Política Interna da IES & 1 & 3 & & 3 & 5 & 12 \\
\hline Cenário Político Externo & & & & & & \\
\hline Quadro de Servidores da IES & 4 & 2 & & 2 & & 8 \\
\hline Planejamento & 5 & 5 & 5 & 5 & 4 & 24 \\
\hline Comunicação Interna & & & & & & \\
\hline Plano de Carreira dos Servidores & & & & & & \\
\hline Rotatividade dos Servidores & & & & & & \\
\hline Tecnologia e Sistemas de Informação & & 1 & 3 & 1 & 2 & 7 \\
\hline Capacitação e Qualificação do Servidor & & & & & 3 & 3 \\
\hline Estrutura Organizacional & & & & & & \\
\hline Legislação & & & & & & \\
\hline Clima Organizacional & & & 1 & & & \\
\hline Proatividade dos Servidores & & & 4 & & & \\
\hline Função Política e Social das IES & & & & & & \\
\hline Competição & & & & & & \\
\hline & & & 2 & & & \\
\hline & & & & & 1 & \\
\hline
\end{tabular}

Fonte: elaborado pelos autores (2016)

Na terceira etapa da Delphi perguntou-se aos especialistas se a partir das cinco variáveis com maior peso apontadas seria possível a simulação de cenários na pró-reitoria de gestão de pessoas da IES. Diante do consenso dos especialistas, a Figura 4 exibe o resultado da terceira rodada.

Figura 4 - Terceira rodada Delphi

\begin{tabular}{|c|c|}
\hline Variáveis Críticas - VC & $\begin{array}{c}\text { Somatória das notas } \\
\text { atribuídas para a VC }\end{array}$ \\
\hline Planejamento & $\mathbf{2 4}$ \\
\hline Política Interna da IES & $\mathbf{1 2}$ \\
\hline Orçamento & $\mathbf{1 1}$ \\
\hline Quadro de Servidores da IES & $\mathbf{8}$ \\
\hline Tecnologia e Sistemas de Informação & $\mathbf{7}$ \\
\hline
\end{tabular}

Fonte: elaborado pelos autores (2016) 
Destaca-se que um especialista entende que a variável "Tecnologia e Sistemas de Informação" poderia ser abordada dentro da variável "Planejamento" e "Orçamento" uma vez que, em sua opinião, cabe ao planejamento institucional preocuparse com a demanda, aquisição e desenvolvimento dos recursos tecnológicos oferecidos aos servidores para o desempenho de suas atividades.

Ainda na visão do especialista a variável "Tecnologia e Sistemas de Informação" está relacionada com o treinamento dos servidores para sua correta operacionalização, ratificando sua opinião da ligação da variável com o planejamento e orçamento da instituição. Por não tratar de uma discordância com a variável apresentada, e sim de uma perspectiva diferente de visão do especialista, ela permaneceu no quadro das mais importantes.

Com o consenso dos especialistas encerrou-se a aplicação da Delphi passando para o segundo nível do modelo.

\section{Nível 2: Inteligência Competitiva}

Este nível corresponde à utilização de ferramentas administrativas que irão compor a inteligência competitiva da pró-reitoria. Neste nível serão organizadas informações que alimentarão e retroalimentarão o sistema de informações para simular os cenários (ROJO, 2005).

Para o presente estudo foram utilizadas a matriz SWOT (forças e fraquezas, ameaças e oportunidades) e o Tableau de Bord (Quadro de Comando) relacionando-as com as variáveis indicadas pelo painel de especialistas no nível 1 , que foram:

- VC1: Planejamento

- VC2: Política Interna da IES

- VC3: Orçamento

- VC4: Quadro de Servidores da IES

- VC5: Tecnologia e Sistemas de Informação

A análise SWOT trata-se de uma ferramenta de diagnóstico que permite identificar as forças e fraquezas internas da organização e as oportunidades e ameaças de seu ambiente externo. Ansoff e McDonnell (1993, p. 55) destacam que "o diagnóstico estratégico é um enfoque sistemático à determinação das mudanças a serem feitas na estratégia e nas potencialidades internas da empresa para garantir êxito em seu ambiente futuro". A Figura 5 apresenta a análise $S W O T$ da Pró-Reitoria.

Figura 5 - Análise $S W O T$

\begin{tabular}{|c|c|}
\hline \multicolumn{2}{|r|}{ SWOT } \\
\hline $\begin{array}{c}\text { Forças } \\
(S)\end{array}$ & $\begin{array}{l}\text { Possibilidade de criação da Universidade Corporativa (VC2). } \\
\text { Equipe multidisciplinar (VC4). } \\
\text { Trabalho em equipe, proatividade, bom relacionamento interpessoal (VC4). } \\
\text { Possibilidade de formação de corpo de instrutores (VC4). } \\
\text { Desenvolvimento do Sistema Integrado de Gestão (SIGRH) compatível com as necessidades } \\
\text { da Pró-Reitoria (VC5). }\end{array}$ \\
\hline $\begin{array}{l}\text { Fraquezas } \\
\qquad(W)\end{array}$ & $\begin{array}{l}\text { Distanciamento das categorias dos técnicos administrativos em educação e docentes } \\
\text { (desvinculação dos docentes com o Plano Anual de Capacitações) (VC4). } \\
\text { Resistência à mudança no que tange a implantação do SIGRH (VC5). } \\
\text { Tempo de resposta de alterações e desenvolvimento dos sistemas internos (VC5). }\end{array}$ \\
\hline $\begin{array}{l}\text { Oportunidades } \\
\qquad(O)\end{array}$ & $\begin{array}{l}\text { Realização de parcerias/convênios com outras instituições (VC1). } \\
\text { Participação no Plano Nacional de Capacitação (VC4). } \\
\text { Integração dos sistemas internos e sistemas de governo (VC5). }\end{array}$ \\
\hline $\begin{array}{l}\text { Ameaças } \\
\qquad(T)\end{array}$ & $\begin{array}{l}\text { Manutenção das políticas de cortes orçamentários (VC3). } \\
\text { Indisponibilidade de instrutores externos para capacitação dos servidores (VC4). } \\
\text { Greve dos servidores (VC4). }\end{array}$ \\
\hline
\end{tabular}

Fonte: elaborado pelos autores (2016) 
As informações levantadas na análise servirão de base no momento da formulação das estratégias do modelo aplicado e posteriormente nas decisões a serem tomadas pelos gestores da unidade.

No que tange ao Tableau de Bord (TB) Costa (2001) explica que ele traduz a visão e a missão da organização em objetivos, a partir dos quais é possível a identificação de fatores críticos de sucessos, que guiarão os gestores nas tomadas de decisões. Segundo Costa (2001) o TB pode conter componentes de diferentes prazos desde que as variáveis críticas exijam que as decisões sejam tomadas para diferentes horizontes de tempo. Para a formulação do TB primeiramente define-se os objetivos da entidade e identificam-se as variáveis chaves, e em segundo lugar, a construção de indicadores por onde o controle da entidade será realizado (Cebrián \& Cerviño, 2004). Na elaboração do TB foram utilizados os objetivos estratégicos vigentes relacionados à política de gestão de pessoas da instituição, contidos no Plano de Desenvolvimento Institucional, conforme pode ser observado na Figura 6.

Figura 6 - Tableau de Bord

\begin{tabular}{|c|c|c|}
\hline Objetivos & Variáveis Chaves & Indicadores \\
\hline $\begin{array}{l}\text { Objetivo 1: Planejar ações } \\
\text { que contribuam ao } \\
\text { desenvolvimento } \\
\text { profissional e pessoal dos } \\
\text { servidores. }\end{array}$ & $\begin{array}{l}\text { VC1: Planejamento } \\
\text { VC2: Política Interna da IES } \\
\text { VC3: Orçamento } \\
\text { VC4: Quadro de Servidores } \\
\text { da IES } \\
\text { VC5: Tecnologia e Sistemas de } \\
\text { Informação }\end{array}$ & $\begin{array}{l}\mathrm{N}^{\circ} \text { de acidentes (VC1). } \\
\text { Programas de conscientização (VC1). } \\
\text { Gastos com capacitação (VC3). } \\
\mathrm{N}^{\circ} \text { de capacitações (VC4). } \\
\mathrm{N}^{\circ} \text { de atendimentos psicológicos } \\
\text { (VC4). } \\
\text { Índice clima organizacional (VC4). }\end{array}$ \\
\hline $\begin{array}{l}\text { Objetivo 2: Desenvolver } \\
\text { projetos que visem o } \\
\text { acompanhamento e } \\
\text { desenvolvimento dos } \\
\text { profissionais da } \\
\text { instituição. }\end{array}$ & $\begin{array}{l}\text { VC1: Planejamento } \\
\text { VC2: Política Interna da IES } \\
\text { VC3: Orçamento } \\
\text { VC4: Quadro de Servidores } \\
\text { da IES } \\
\text { VC5: Tecnologia e Sistemas de } \\
\text { Informação }\end{array}$ & $\begin{array}{l}\mathrm{N}^{\circ} \text { de projetos de capacitação interna } \\
\text { (VC4). } \\
\text { Absenteísmo (VC4). } \\
\mathrm{N}^{\circ} \text { de servidores lotados em unidades } \\
\text { de correlação com sua formação } \\
\text { profissional (VC1). }\end{array}$ \\
\hline
\end{tabular}

Fonte: elaborado pelos autores (2016)

A elaboração do TB permitiu o alinhamento entre os objetivos institucionais com as variáveis críticas levantadas pelos especialistas de modo a subsidiar a formulação das estratégias e dos planos de ação posteriormente.

\section{Nível 3: Simulação de Cenários}

A partir dos dados coletados, a variável escolhida para a simulação dos cenários foi a VC4
(Quadro de Servidores da IES) pelo fato dela estar relacionada com maior frequência nas informações coletadas no momento da construção da inteligência competitiva. Destaca-se que por se tratar de uma próreitoria de gestão de pessoas a variável escolhida para a simulação dos cenários é altamente influenciável no desempenho de suas atividades principais. A Figura 7 apresenta os cenários simulados. 
Simulação de Cenários na Pró-Reitoria de Gestão de Pessoas de uma Instituição de Educação Superior Pública do Oeste do Paraná

Figura 7 - Simulação dos cenários

\begin{tabular}{|c|l|}
\hline CENÁRIO & \multicolumn{1}{|c|}{ SIMULAÇÃO } \\
\hline C1 & $\begin{array}{l}\text { O quadro de servidores se reduz, aumentando assim o volume de serviço na } \\
\text { instituição; aumento da taxa de absenteísmo; servidores desmotivados; menor } \\
\text { possibilidade de capacitações e formações de instrutores; maior distanciamento } \\
\text { entre as categorias; movimentos de greve. }\end{array}$ \\
\hline C2 & $\begin{array}{l}\text { Há uma estabilidade no quadro de servidores, mantendo-se uma equipe } \\
\text { multidisciplinar, possibilitando a formação de instrutores internos para capacitação } \\
\text { dos demais servidores, entretanto com certa resistência às mudanças nos sistemas } \\
\text { de informação. }\end{array}$ \\
\hline C3 & $\begin{array}{l}\text { O quadro de servidores contemplará profissionais altamente qualificados e } \\
\text { integrados, participando de programas de capacitação interna, programas de } \\
\text { prevenção, saúde e qualidade de vida do trabalhador, melhorando assim a qualidade } \\
\text { do serviço público e a motivação dos servidores. }\end{array}$ \\
\hline
\end{tabular}

Fonte: elaborado pelos autores (2016)

Para a projeção dos cenários abordou-se três perspectivas: uma pessimista, representada pelo cenário C1, uma neutra, representado a manutenção do cenário atual, C2, e por fim uma otimista contemplada na descrição C3.

Nível 4: Formulação de Estratégias
Foram elaboradas estratégias para cada um dos cenários simulados, o que proporciona maior velocidade no tempo de resposta nas diversas possibilidades de acontecimentos (ROJO; 2005), conforme apresentado na Figura 8.

Figura 8 - Formulação de estratégias

\begin{tabular}{|l|l|}
\hline \multicolumn{1}{|c|}{ Cenários Simulados } & \multicolumn{1}{c|}{ Estratégias Formuladas } \\
\hline C1 & E1 \\
Quadro de servidores desqualificado. & $\begin{array}{l}\text { a) Nomeação de novos servidores. } \\
\text { b) Melhor distribuição de atividades. } \\
\text { c) Programas de qualidade no trabalho. } \\
\text { d) Desenvolvimento dos sistemas de informação. }\end{array}$ \\
\hline C2 & $\begin{array}{l}\text { E2 } \\
\text { Quadro de servidores estável. }\end{array}$ \\
& $\begin{array}{l}\text { a) Programas de desenvolvimento profissional. } \\
\text { c) Programa de avaliação institucional. } \\
\text { d) Melhoria dos processos internos. }\end{array}$ \\
\hline & $\begin{array}{l}\text { E3 } \\
\text { Quadro de servidores bem qualificado. }\end{array}$ \\
& $\begin{array}{l}\text { a) Maior número de capacitações internas. } \\
\text { b) Política de redução de custos. } \\
\text { c) Gestão por competência. }\end{array}$ \\
\hline
\end{tabular}

Fonte: elaborado pelos autores (2016) 
Na sequência, o quinto nível do modelo compreende na formulação do plano de ação da próreitoria para o atingimento das estratégias formuladas.

Nível 5: Plano de Ação
É no plano de ação que ocorre o alinhamento das estratégias com as metas desenvolvidas para cada um dos três cenários simulados (ROJO, 2005). A Figura 9 apresenta o plano de ação formulado para a instituição.

Figura 9 - Plano de ação

\begin{tabular}{|c|c|}
\hline Estratégias Formuladas & Metas \\
\hline $\begin{array}{l}\text { E1 } \\
\text { a) Nomeação de novos servidores. }\end{array}$ & $\begin{array}{l}\text { M1 } \\
\text { Aproveitamento de lista de cadastro de reserva ou realização } \\
\text { de concurso público até dezembro de } 2015 \text {. } \\
\text { M2 }\end{array}$ \\
\hline b) Melhor distribuição de atividades. & $\begin{array}{l}\text { Avaliar o manual de atribuições da instituição e elaborar o } \\
\text { manual do servidor até novembro de } 2015 \text {. }\end{array}$ \\
\hline c) Programa de qualidade de vida no & M3 \\
\hline trabalho. & $\begin{array}{l}\text { Iniciar cursos e palestras voltados para a motivação, saúde, } \\
\text { segurança e qualidade de vida no trabalho até meados de } \\
\text { outubro } 2015 \text {. }\end{array}$ \\
\hline d) Desenvolvimento dos sistemas de & M4 \\
\hline informação. & $\begin{array}{l}\text { Adequação dos sistemas de informação para as atividades da } \\
\text { pró-reitoria e da instituição com as primeiras implantações de } \\
\text { melhorias em novembro de } 2015 \text {. }\end{array}$ \\
\hline $\mathbf{E 2}$ & M1 \\
\hline $\begin{array}{l}\text { a) Programas de desenvolvimento } \\
\text { profissional. }\end{array}$ & $\begin{array}{l}\text { Fortalecer as ações de incentivo a qualificação por meio da } \\
\text { educação formal e cursos de capacitação até início de fevereiro } \\
\text { de } 2016 \text {. } \\
\text { M2 }\end{array}$ \\
\hline $\begin{array}{l}\text { b) Treinamento em sistemas de } \\
\text { informação. }\end{array}$ & $\begin{array}{l}\text { Iniciar treinamentos sobre os sistemas de informações de } \\
\text { dados para habilitar e sensibilizar os servidores até janeiro de } \\
2016 \text {. }\end{array}$ \\
\hline & M3 \\
\hline c) Avaliação institucional. & $\begin{array}{l}\text { Elaborar programa de avaliação institucional para } \\
\text { identificação de melhorias no ambiente de trabalho dos } \\
\text { servidores até janeiro de } 2016 \text {. } \\
\text { M4 }\end{array}$ \\
\hline d) Melhoria dos processos internos. & $\begin{array}{l}\text { Mapear e avaliar os principais processos da pró-reitoria e da } \\
\text { instituição visando melhor desempenho das atividades até } \\
\text { março de } 2016 \text {. }\end{array}$ \\
\hline $\mathbf{E 3}$ & M1 \\
\hline $\begin{array}{l}\text { a) Maior número de capacitações } \\
\text { internas. }\end{array}$ & $\begin{array}{l}\text { Aumentar o número de capacitações internas a fim de } \\
\text { valorizar os servidores até março de } 2016 \text {. } \\
\text { M2 }\end{array}$ \\
\hline b) Política de redução de custos. & $\begin{array}{l}\text { Nomear equipe para avaliar os gastos da pró-reitoria e criar } \\
\text { índices de controle até junho de } 2016 \text {. } \\
\text { M3 }\end{array}$ \\
\hline c) Gestão por competência. & $\begin{array}{l}\text { Implantar uma gestão por competências para melhor } \\
\text { aproveitamento dos servidores até junho de } 2016 \text {. } \\
\text { M4 }\end{array}$ \\
\hline $\begin{array}{l}\text { d) Criação da universidade } \\
\text { corporativa. }\end{array}$ & $\begin{array}{l}\text { Formular uma proposta com programas de capacitação } \\
\text { voltados para gestão organizacional e alinhamento estratégico } \\
\text { das unidades com a instituição até julho de } 2016 \text {. }\end{array}$ \\
\hline
\end{tabular}

Fonte: elaborado pelos autores (2016) 


\section{RESULTADOS OBTIDOS E ANÁLISE}

Tendo em vista o objetivo de simular cenários para a Pró-Reitoria de Gestão de Pessoas de uma IES, primeiramente aplicou-se a técnica Delphi para identificação de variáveis críticas para a simulação de cenários para a pró-reitoria de gestão de pessoas da IES. A segunda etapa correspondeu a análise SWOT com objetivo de identificar pontos positivos e negativos relacionados a IES. A partir dos dados coletados nas etapas anteriores foram simulados três cenários, um pessimista, um intermediário e um otimista.

A aplicação do modelo Rojo de simulação de cenários tornou possível a complementação do planejamento estratégico da pró-reitoria de gestão de pessoas da instituição. O modelo Rojo de simulação de cenários se apresentou oportuno ao simular ambientes futuros, desta forma, os gestores anteciparam-se diante de incertezas e possibilidades que possam a vir ocorrer no ambiente de trabalho. Os resultados encontrados nesta produção técnica convergem com os estudos de Brandalise et al. (2012) e Hoss et al. (2012) que aplicaram o modelo de simulação de cenários e possibilitaram às organizações a elaboração de estratégias para as possíveis contingências do mercado. Para Rojo (2005) o modelo auxilia no processo de tomada de decisão das organizações.

Diante do planejamento estratégico da IES, a pró-reitoria pode apresentar o seu próprio planejamento não mais somente baseado em dados passados e sim também com base na previsão de cenários futuros. Em posse das estratégias formuladas diminui-se o grau dos impactos negativos caso não houvesse previsão dos acontecimentos. Por fim, o método de intervenção utilizado identificou variáveis críticas que servirão como base para demais instituições na elaboração de suas estratégias, além de poder ser adotado pelas demais pró-reitorias para que estas também estejam preparadas para as incertezas do ambiente.

\section{CONCLUSÃO}

O objetivo do presente relato técnico foi simular cenários para a Pró-Reitoria de Gestão de Pessoas de uma IES do oeste do Paraná. Por meio do modelo Rojo de simulação de cenários, que aborda a técnica investigativa Delphi, ferramentas administrativas e a interação entre pesquisador e especialistas, foi possível a projeção de três cenários. Em posse dos cenários foi possível traçar estratégias e um plano de ação para que a pró-reitoria pudesse se precaver de acontecimentos indesejáveis no decorrer de suas atividades quanto à indisponibilidade orçamentária do ano de 2015.

A limitação encontrada neste trabalho está vinculada a coleta de informações com especialistas de outras instituições de educação superior similares, tendo em vista que para consultar as opiniões dos especialistas destas instituições era necessário recorrer a entidades localizadas em outras cidades do estado, deixando a fase de coleta de dados com os especialistas mais demorada.

Para trabalhos futuros com foco em instituições de ensino, recomenda-se a observação das variáveis críticas identificadas neste relato. Destaca-se também como oportunidade de estudo a aplicação do modelo nas demais unidades de instituições de educação superior pública ou privada e também na totalidade destas IES.

\section{REFERÊNCIAS}

Ansoff, H., \& McDonnell, E. J. (1993). Implantando a administração estratégica. São Paulo: Atlas.

Brandalise, L. T., Rojo, C. A., Mata, D. M., \& Souza, A. F. de. (2012). Simulação de cenários e formulação de estratégias competitivas: o caso do atacado Liderança. Revista Gestão e Tecnologia, 12(3), pp. 223-257.

Decreto $n^{o}$ 8.389, de 7 de janeiro de 2015 (2015). Dispõe sobre a execução orçamentária dos órgãos, dos fundos e das entidades do Poder Executivo até a publicação da Lei Orçamentária de 2015. Brasília, DF. Recuperado em 10 de maio, 2017, de http://www.planalto.gov.br/ccivil_03/_Ato20152018/2015/Decreto/D8389.htm

Cebrián, M. S., \& Cerviño, E. F. Un análisis de la flexibilidad del cuadro de mando integral (CMI) em su adaptación a la naturaliza de las organizaciones. Revista Iberoamericana de Contabilidad de Gestión. 2(4).

Certo, S., \& Peter, J. P. (1993). Administração estratégica: planejamento e implantação da estratégia. São Paulo: Makron Books.

Costa, A. P. P. da. (2001). Contabilidade gerencial: um estudo sobre a contribuição do Balanced Scorecard. Dissertação de mestrado. Faculdade de Economia, Administração e Contabilidade da Universidade de São Paulo, São Paulo, SP, Brasil.

Denzin, N. K., \& Lincoln, Y. S. (2006). O planejamento da pesquisa qualitativa: teoria $e$ abordagens. ( $2^{\mathrm{a}}$ ed.). Porto Alegre: Artmed.

Ghemawat, P. (2000). A estratégia e o cenário de negócios: textos e casos. Porto Alegre: Bookman. 
Godoy, A. S. (1995). Introdução à pesquisa qualitativa e suas possibilidades: uma revisão histórica dos principais autores e obras que refletem esta metodologia de pesquisa em ciências sociais. Revista de Administração de Empresas, 35(2), pp. 57-63.

Gonçalves, R. R., Torres, A. P., Rodrigues, M. R. A., \& Zygielszyper, N. R. (2011). Cenários econômicos e tendências. Rio de Janeiro: Editora FGV.

Hoss, O., Bromberger, V., Rojo, C. A., \& Sousa, A. F. (2012). Simulação de cenários: estudo nas fontes de recursos da fundação de apoio à educação, pesquisa e desenvolvimento científico e tecnológico da universidade tecnológica federal do Paraná campus Pato Branco. Revista Ibero-Americana de Estratégia-RIAE, 11(3), pp. 172-204.

Mintzberg, H., Lampel, J., Quinn, J. B., \& Ghoshal, S. (2006). O processo da estratégia: conceitos, contextos e casos selecionados. (4 ${ }^{\mathrm{a}}$ ed.). Porto Alegre: Artmed.
Oliveira, D. de P. R. de. (1999). Planejamento estratégico: conceitos, metodologia e práticas. $\left(14^{\mathrm{a}}\right.$ ed.). São Paulo: Atlas, 1999.

Porter, M. E. (1986). Estratégia competitiva: técnicas para análise de indústrias e da concorrência. ( $7^{\mathrm{a}}$ ed.). Rio de Janeiro: Campus.

Rojo, C. A. (2005). Modelo para simulação de cenários: uma aplicação em instituição de ensino superior privada. Tese de doutorado. Universidade Federal de Santa Catarina, Florianópolis, SC, Brasil.

Sokoloski, P. K. M. (2007). O relacionamento entre incerteza ambiental percebida, estratégia organizacional, grupos estratégicos e desempenho. Dissertação de mestrado. Pontifícia Universidade Católica do Paraná, Curitiba, PR, Brasil.

Tachizawa, T., \& Rezende, W. (2002). Estratégia empresarial: tendências e desafios - um enfoque na realidade brasileira. São Paulo: Makron Books.

Thiollent, M. (2011). Metodologia da pesquisa-ação. (18 a ed.). São Paulo: Cortez. 